Boise State University

ScholarWorks

$7-2013$

The Need to Adapt the Exploration Model from the Oil Patch to Contaminated-Site Characterization: A Case from Hill AFB, Utah, USA

John H. Bradford

Boise State University

Esther Babcock

Boise State University 


\title{
The need to adlapt the exploration model from the oil patch to contaminated-site characterization: A case from Hill AFB, Utah, USA
}

\author{
John H. BRADFORD and ESTHER BABCOCK, Boise State University
}

$F^{o}$ r decades, the oil industry has employed a working model for hydrocarbon exploration in which large-scale geophysical surveys are undertaken prior to a second phase of intensive, targeted drilling. This latter phase may be conducted in conjunction with further focused geophysical studies. The geophysical surveys provide lateral coverage and continuity that are used to drive placement of drilling locations. The reason for this approach is simple: wells are expensive relative to geophysical surveys. Also, practical limits on lateral coverage preclude optimization of exploration targets based on well information alone.

In concept, the problem of contaminated-site characterization is analogous to oil exploration; yet in practice, managers have been slow to adopt the use of geophysics at the front end of a characterization project. A more common scenario is that drilling serves as the primary exploration tool. If geophysics is used, it is often at a later stage of characterization and often only after well data are demonstrated inadequate. The reason for the reluctance to deploy geophysics first is not entirely clear. Certainly the economic drivers are similar-the lateral coverage afforded by geophysical methods in the near surface is continuous and relatively inexpensive compared to drilling or other direct sampling methods such as a cone penetrometer.

We can make some key observations that may provide some insight into the reluctance to apply geophysics: (1) site managers are more likely to have an engineering background and may have little or no exposure to geophysics in their training-lack of experience leads to suspicion of "soft" geophysical data, and (2) the economy of contaminated-site characterization is driven by punitive interests, or rather fear of punitive action, whereas oil exploration is profit-driven. The latter may lead to a greater willingness to take risk. Taken together, these observations may reveal why a culture has evolved that does not utilize geophysics as part of its bestpractices working model. However, given the substantial economic and technical advantages resulting from the use of geophysics, we as geophysicists must continue to push education of site managers with the goal of bringing the full benefit of geophysical methods to bear on keeping our water supply safe and clean.

This article presents an example from Hill Air Force Base (AFB), Utah. This site is typical of many U.S. Department of Defense and Department of Energy installations that dumped large quantities of liquid waste into open pits in the decades between 1940 and 1980 . This misguided practice has left a legacy of clean-up problems, many of which remain to be solved. Common contaminates include light nonaqueousphase liquids (LNAPL), typically light hydrocarbons (fuels), and dense nonaqueous-phase liquids (DNAPL) — chlorinated solvents are common examples.

\section{Field site}

At Operable Unit 1 (OU-1), a variety of both LNAPL and DNAPL contaminants was dumped in two chemical disposal pits (CDPs 1 and 2) and burned from the early 1940s to 1973. Noncombusted liquids leaked from the CDPs to the underlying aquifer in significant quantities and now comprise a free-product plume that covers approximately seven acres with measured thickness of as much as $0.3 \mathrm{~m}$. The plume is a highly heterogeneous mixture composed primarily of jet fuel and light lubricating oil with a significant dissolved solvent phase. In addition to the floating pool, the contaminant accumulates in a smear zone that is controlled by water-table fluctuations, with the relative amounts of pooled and smeared NAPL dependent on water-table elevation. The plume resides in the $6-10 \mathrm{~m}$ of gravel to silty sand that comprises the Provo alluvium and overlies the clays of the Alpine Formation. The Alpine clay acts as an aquitard and the water table fluctuates about the sand/clay boundary on an annual cycle.

Previous work by Lien and Enfield (1998) indicated that contaminated soil at the site has relatively low electric conductivity. This observation, coupled with favorable results of previous GPR imaging work (Young and Sun, 1996; Young and Sun, 1998), led us to select Hill AFB as a research site for developing and testing various GPR imaging methods to detect NAPL contaminants.

An initial characterization of OU-1 was conducted in the early 1980s which consisted of NAPL, water, and lithologic measurements in three boreholes. Based on this rather limited information, an impermeable containment barrier was installed in an attempt to prevent further migration of the contaminant plume (CH2MHILL, 2008). Because the aquitard surface was poorly characterized, the barrier was not properly keyed into the clay aquitard. This installation problem, coupled with an ineffective barrier design, led to poor containment performance.

Additionally, the initial characterization effort missed a substantial portion of the plume which lies outside the first containment barrier. In 1995, a more extensive characterization effort was completed and, by 2001, a second remediation/containment system had been designed and implemented. This system consisted of extraction trenches which were designed to be keyed into the underlying clay aquitard.

Site managers in the 1990s and 2000s were interested in methods to improve site-characterization technology in general, and welcomed and encouraged researchers to test methodologies at OU-1. As the result of a number of research studies coupled with the detailed characterization and remediation efforts, some 1200 borings, cores, and cone-penetrometer tests were completed at the seven-acre site between 1980 and 2000 (Figure 1). Over this time, multimillions of 


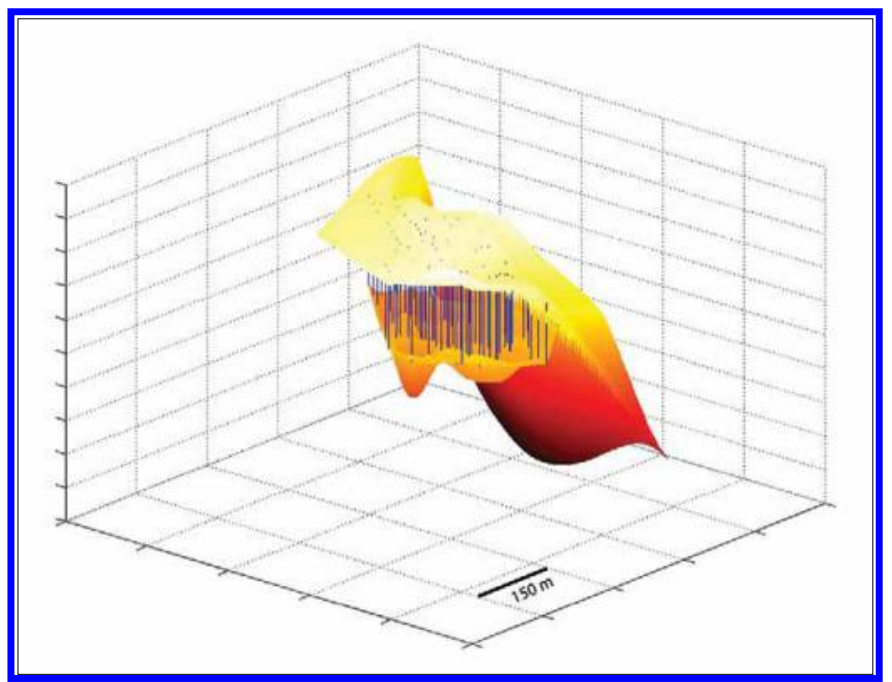

Figure 1. Image of the land surface at OU-1 and underlying clay aquitard surface. Borehole and CPT positions (shown in blue) form a veritable well forest.

dollars were spent on characterization and remediation but, until 2001, characterization using geophysics was used only for focused research on an ad-hoc basis. In 2001, as part of an effort to develop a detailed contaminant flow and transport model, it was determined that the site was not adequately characterized despite the vast database of borehole and CPT measurements (Sverdrup Technology Inc. and Intera Inc., 2003). At this time, a third round of characterization was initiated in which our team conducted an extensive groundpenetrating radar (GPR) survey to produce a detailed map of the clay aquitard and to explore for previously unidentified NAPL accumulations.

The work proceeded in two phases. Phase 1 consisted of a large-scale, pseudo 3D single-offset GPR survey designed to produce a detailed map of the surface of the clay aquitard. Analysis of these data led to identification of several reflectivity and topographic anomalies thought likely to indicate the presence of NAPL. Phase 2 consisted of targeted, continuous multifold GPR acquisition coupled with reflection tomography and prestack depth migration to evaluate the reflectivity and topography anomalies for elevated radar propagation velocity, which is consistent with NAPL contamination. Finally, these results guided a subsequent intensive cone-penetrometer (CPT) campaign. The CPT was equipped with a laser-induced fluorescence (LIF) sensor and coupled with chemical analyses of borehole samples.

\section{Detecting NAPL contamination with GPR}

GPR is sensitive to relative dielectric permittivity $(\mathrm{K})$ and effective electric conductivity $(\sigma)$. The velocity of GPR signal propagation is a function of $\mathrm{K}$. Water has very high permittivity (K 81), whereas common NAPL contaminants such as light hydrocarbons and chlorinated solvents have very low permittivity $(\mathrm{K} \sim 2)$ and are poor conductors. Anomalous displacement of water with low-permittivity NAPL leads to lower bulk permittivity and conductivity than the surrounding sediments. However, weathering processes can

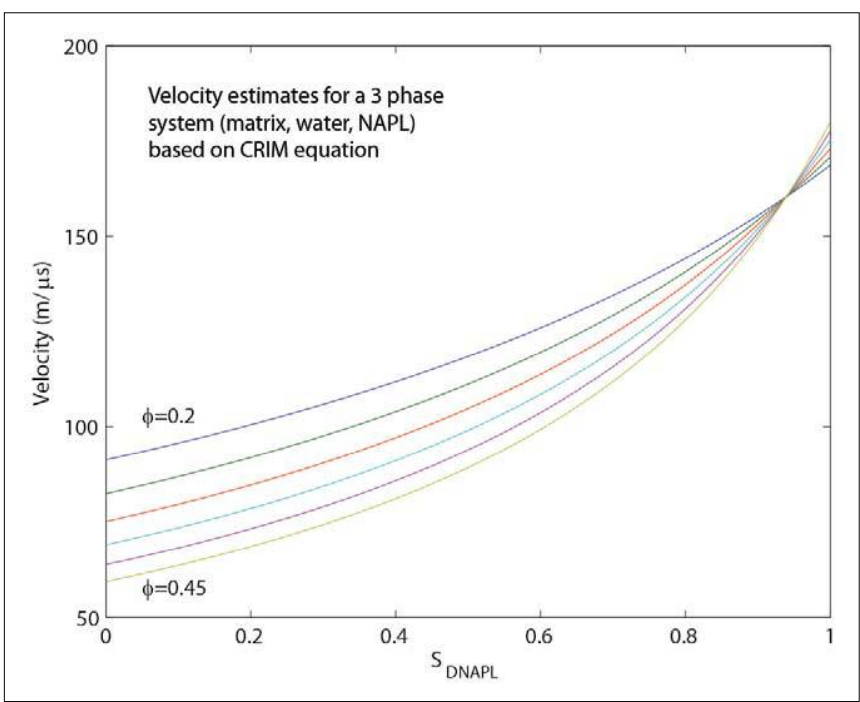

Figure 2. Electromagnetic wave propagation velocity as a function of NAPL concentration and porosity. As the mixture grades from full water saturation to full NAPL saturation, the velocity may increase by a factor of 3 .

lead to departure from this conceptual model; when light hydrocarbons undergo biodegradation, organics acids can be produced that dissolve mineral grains ultimately leading to higher dissolved solid concentration and an increase in electrical conductivity (Atekwana et al., 2004a; Atekwana et al., 2002; Atekwana et al., 2004b). Field evidence from one site indicates that even when the conductivity increases, the bulk permittivity of the system remains low following what would be predicted for unaltered NAPL (Bradford and Wu, 2007).

The GPR signature associated with the presence of NAPL may be manifest in three ways. First, the decrease in dielectric permittivity results in increased EM propagation velocity (Figure 2). Second, the decrease in permittivity can significantly change reflectivity. Finally, the electric conductivity may increase or decrease depending on the state of NAPL biodegradation, thereby producing anomalous GPR attenuation.

\section{GPR methods}

Most GPR surveys are acquired with a constant transmitterreceiver offset. This approach is especially valuable as a rapid reconnaissance tool. However, as the complexity of the electromagnetic (EM) velocity structure increases, the ability to produce useful images using this simple acquisition geometry diminishes. In the absence of diffraction hyperbolae, velocity cannot be measured directly from common-offset data, and reflector depth estimates must be based on rough guesses of material velocity or correlation of interpreted reflectors with known material boundaries. In contrast, continuous multioffset data acquisition enables velocity estimation at all locations.

Often in GPR investigations, large velocity gradients violate the underlying assumptions of normal-moveout (NMO) velocity analysis. To properly treat this problem, we utilize prestack depth migration (PSDM) which has been shown to be effective for GPR data by several authors (Bradford, 
2006; Bradford, 2008; Leparoux et al., 2001; Pipan et al., 2003). Because prestack migration velocity analysis is an integral component of PSDM, one byproduct is a detailed and accurate velocity model. The velocity model itself provides important material property information and which can be exploited to identify NAPL-induced anomalies.

\section{Previous GPR investigations at Hill AFB}

Young and Sun (1996) reported the results of a $1858-\mathrm{m}^{2} \mathrm{GPR}$ survey acquired just north of CDP 1. Based only on NMO velocity analysis at a few locations, Young and Sun concluded that the presence of NAPL would not introduce sufficient contrast in electrical properties for detection using GPR. However, we suspected that the increased accuracy afforded by PSDM velocity analysis could overcome the limitations of NMO processing and potentially identify NAPL induced velocity anomalies.

In October 2000, our group conducted a research scale, 3D, multi-offset GPR survey. Survey parameters were designed to target an anomaly that had been identified in an earlier feasibility study. The survey covered $2973 \mathrm{~m}^{2}$ and produced an excellent quality data set with resolution on the order of $0.3-0.6 \mathrm{~m}$ vertically and $0.6-1.2 \mathrm{~m}$ horizontally. From these data, we identified a topographic low on the clay surface (Figure 3). Using PSDM velocity analysis, we found a zone of anomalously high radar velocity just above the low in the clay surface (Figure 3). Thus, we identified both an inverted stratigraphic trap and physical properties consistent with an NAPL-rich zone. This interpretation was verified in a subsequent soil sampling and NAPL characterization study where NAPL saturation up to $4 \%$ was found within the anomalous zone (Bradford and Deeds, 2006). These results helped guide our interpretation of the 2002 survey.

\section{Site-wide pseudo 3D, single-offset survey}

In 2002, our group acquired 19,092 line-m of common-offset GPR data in an orthogonal grid to map the clay aquitard surface beneath the entire OU-1 site. Data were acquired with a Sensors and Software PulseEKKO 100A system with $50-\mathrm{MHz}$ antennas with 7.6-m line spacing for lines oriented NS and 30.5-m line spacing for lines oriented EW (Figure 4a). The western portion of the survey area was not within the orthogonal grid, but lines were curvate, parallel, and had $7.6-\mathrm{m}$ spacing between lines. A constant velocity of $0.12 \mathrm{~m} /$ ns was used for depth conversion based on the results of previous multi-offset GPR studies. Data were generally of high quality and the clay aquitard surface was easily identified. Gaps in coverage (Figure 4a) occur where the clay surface could not be identified either because of high signal attenuation (possibly caused by inorganic contaminants and/or biodegradation of NAPL) or to high levels of coherent noise.

We integrated clay depths picked from the GPR data with available well information and produced a detailed map of the clay surface topography (Figure $4 \mathrm{~b}$ ). Subsequent CPT sampling of the clay surface at 45 locations across the site agreed with the GPR-controlled clay surface map to within a standard deviation of $\pm 0.78 \mathrm{~m}$. This result is $\sim 1 / 4$ wavelength
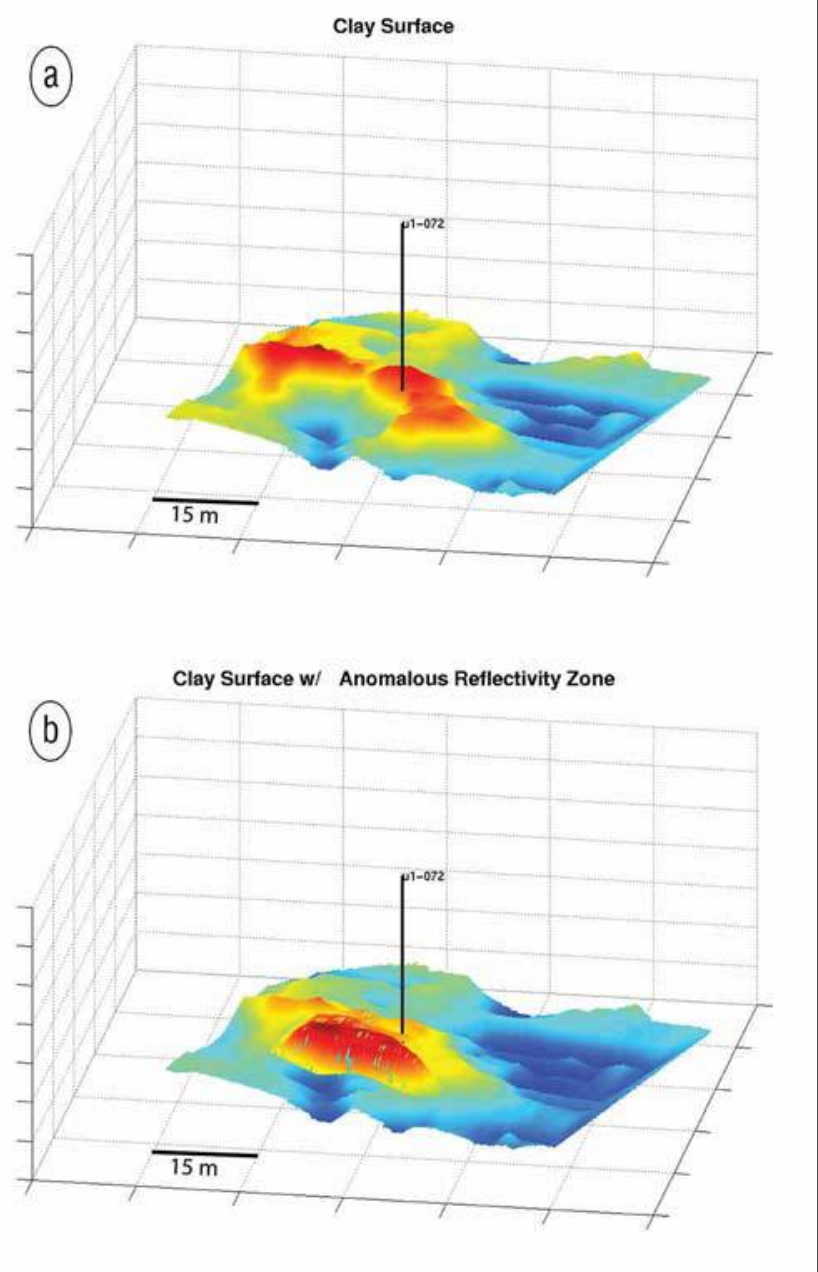

Figure 3. (a) 3D map of the clay aquitard surface constructed from a 3D multi-offset GPR survey designed to investigate the bowl-shaped topographic low adjacent to well U1-072. (b) Clay surface with the upper surface of a high-velocity zone that forms an umbrella over the topographic low. Subsequent borehole sampling showed NAPL concentrations as high as $4 \%$ within the high-velocity zone.

at the dominant frequency of the signal, $40 \mathrm{~Hz}$, with an average velocity of $-0.12 \mathrm{~m} / \mathrm{ns}$ gives a wavelength of $3 \mathrm{~m}$. Such excellent agreement between data sets validates the mapping strategy. By comparing the GPR-produced map with that produced from 87 borehole and CPT points alone (Figure $4 c)$, it is clear that the GPR survey produced a dramatically improved map of the clay surface (Figure 4b). In the GPR map, many details are identified that are completely missed in the map produced from direct sampling data (borehole and CPT) alone. Note that this relatively low-cost GPR survey was completed in just five days, with a crew of two people, and at a cost that was roughly equivalent to the cost of three shallow boreholes.

\section{Multi-offset data acquisition and processing}

Based on areas thought to be most critical for remediation, we identified four areas for multi-offset investigation (Figure 5). We sought to locate electric property anomalies potentially associated with NAPL contamination, and to improve the 
clay surface interpretation in high noise areas. We prioritized based on the expected potential for NAPL contamination, lack of preexisting well control, and potential for successful imaging based on previous experience at the site. Area 1 targets a northeast-trending depression which may be an important off-site contaminant transport route. Area 2 targets the poor data quality area in the vicinity of the site's power line. Area 3 targets the deepest channel that trends WSW from the CDPs. Little control is available for this potentially important transport pathway. Area 4 targets the poor data quality area roughly centered on the CDPs. Additionally,

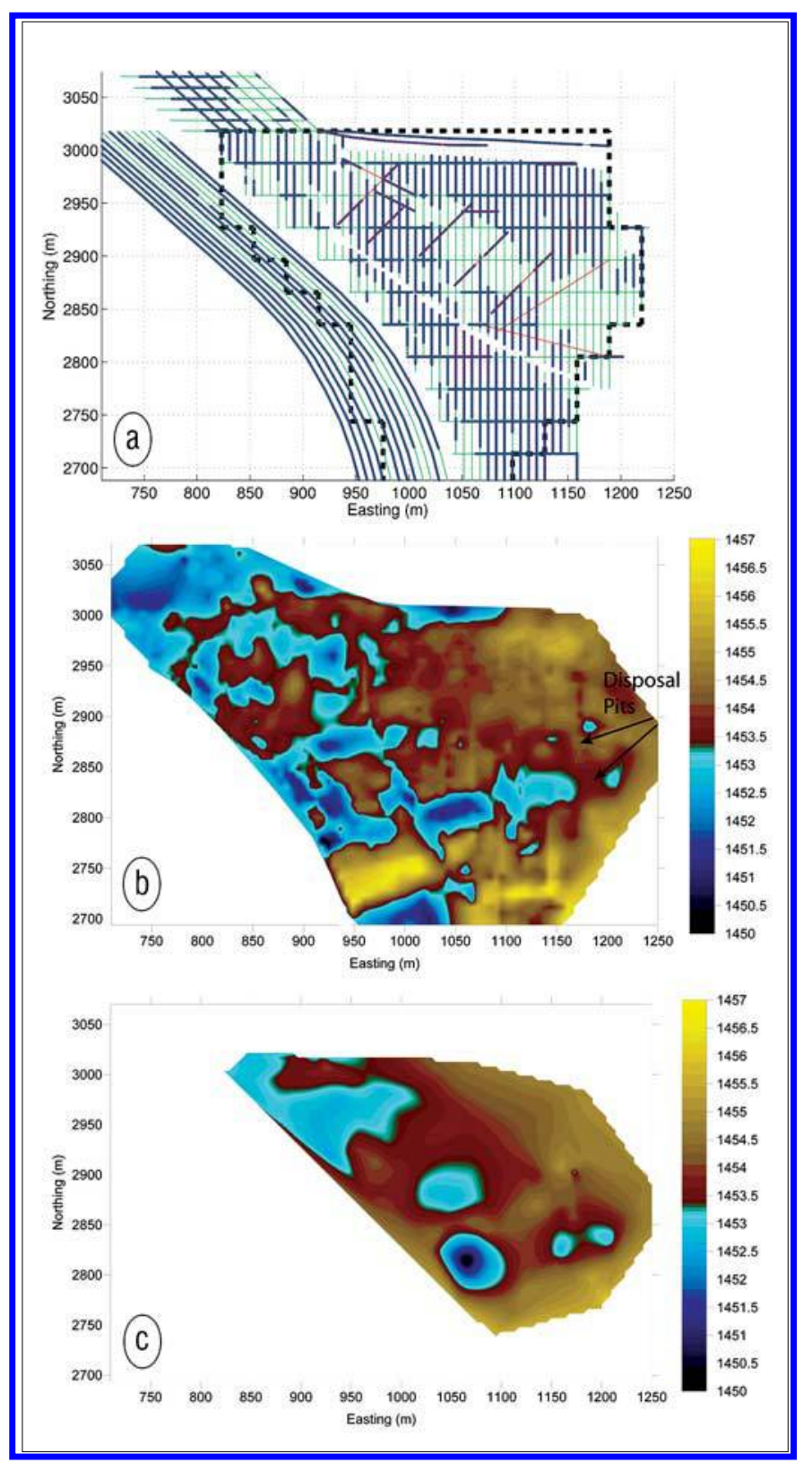

Figure 4. (a) GPR coverage over site OU-1: heavy blue lines show locations where the clay aquitard could be identified, red indicates the location of multi-offset profiles. (b) Clay aquitard map derived from GPR measurements and boreholes showing a complex system of paleochannels that drain toward the southwest during low water-table conditions. (c) Clay aquitard map derived from wells alone which does not adequately characterize the channel system. we investigated three reflectivity anomalies north of $2930 \mathrm{~m}$ North and east of $1040 \mathrm{~m}$ East (Figure 5). Acquisition parameters are listed in Table 1.

Detailed processing emphasized noise reduction and velocity analysis to identify electric property anomalies potentially associated with NAPL contamination. Key processing steps included time zero correction; band-pass filter

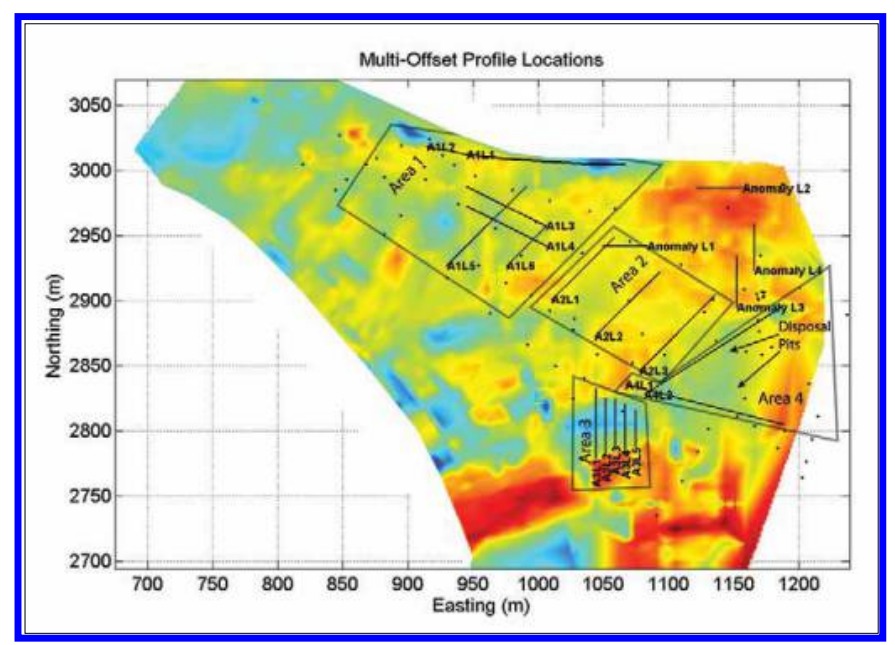

Figure 5. Map of the four areas identified for detailed multi-offset investigation. Anomaly lines cross features similar to those shown in Figure 3. Area 3 is focused on the deepest paleochannel present at the site. Black dots show previous well locations.

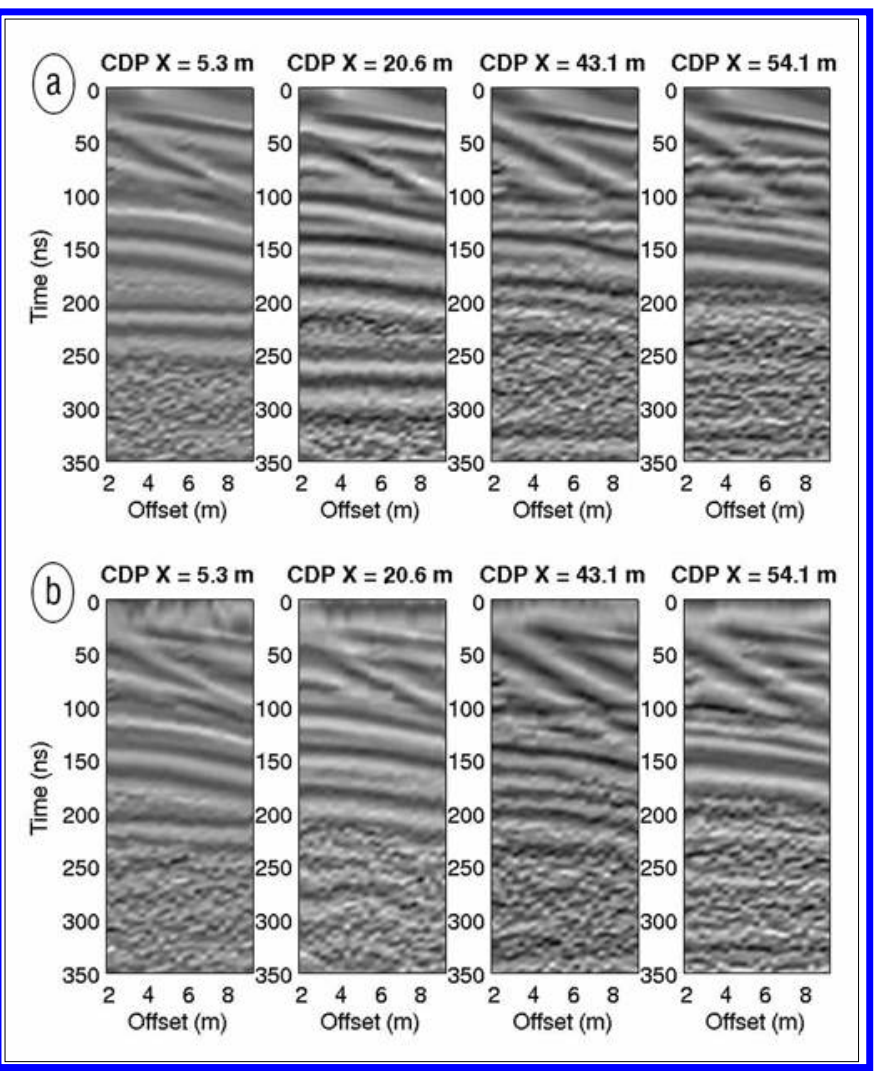

Figure 6. (a) CDPs along line A3L1 (Figure 5) showing heavy contamination with air waves scattered from out-of-plane fences (horizontal events in the upper set of CDPs). (b) Prestack $\mathrm{f}-\mathrm{k}$ filtering is effective for removing air-wave noise. 


\begin{tabular}{|l|l|}
\hline System & $\begin{array}{l}\text { Single channel, Sensors and Software } \\
\text { PE 100A }\end{array}$ \\
\hline Antennas & $50 \mathrm{MHz}$ \\
\hline Geometry & Common source point \\
\hline Source interval & $0.6 \mathrm{~m}$ \\
\hline Receiver interval & $0.3 \mathrm{~m}$ \\
\hline Source fold & 25 \\
\hline Near offset & $2 \mathrm{~m}$ \\
\hline Recording time & $500 \mathrm{~ns}$ \\
\hline Sampling interval & $1.6 \mathrm{~ns}$ \\
\hline Vertical stacks/trace & 32 \\
\hline
\end{tabular}

Table 1. Acquisition parameters for multifold surveys.
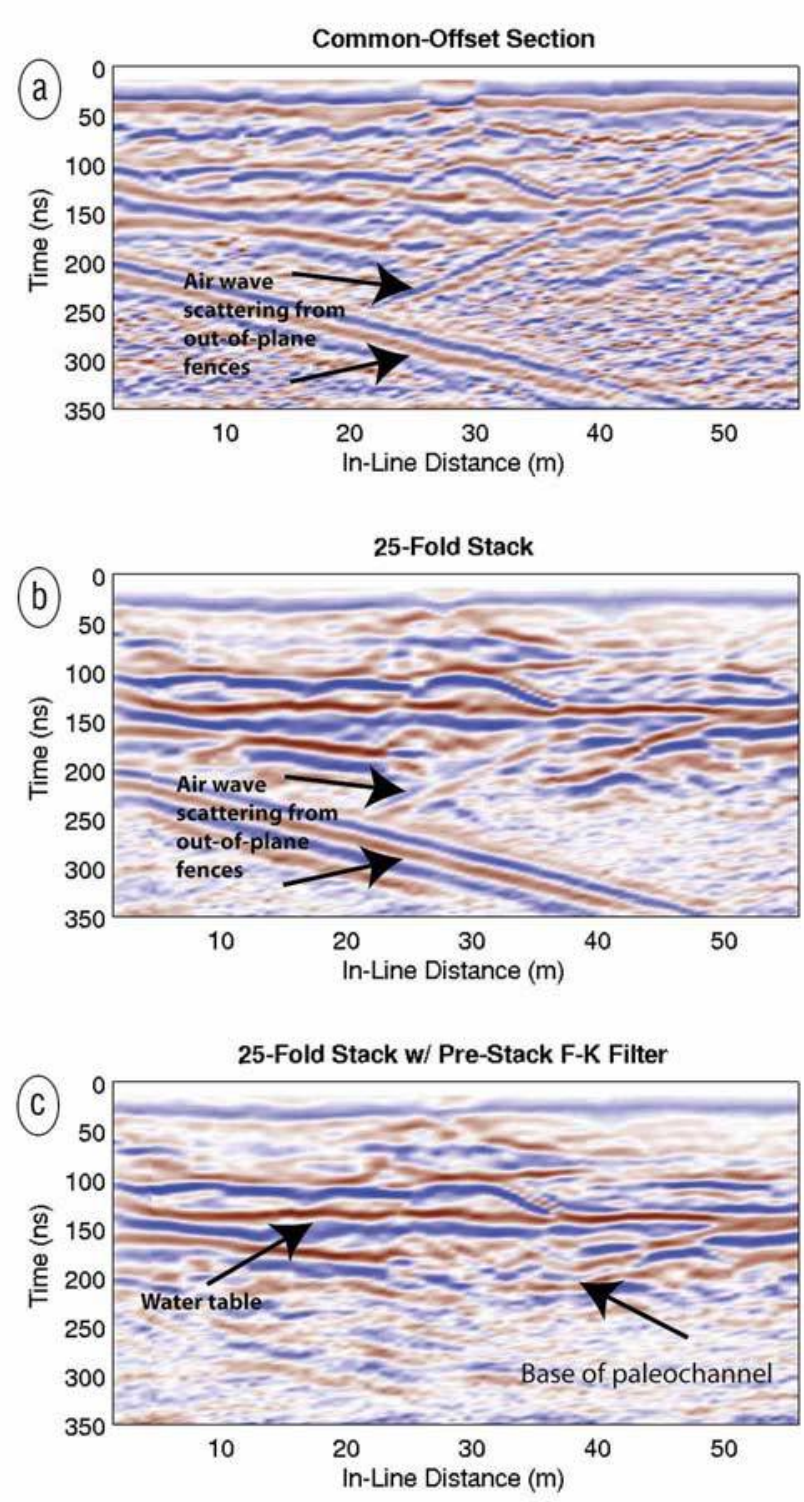

Figure 7. (a) Standard common-offset radar image of line A3L1 (Figure 5) that is heavily contaminated with out-of-plane air-wave scatter. (b) Stacking alone cannot adequately attenuate the air-wave noise. (c) Prestack $\mathrm{f}-\mathrm{k}$ filtering in the CDP domain virtually removes all air-wave noise revealing the base of the paleochannel.
(12-25-100-200 MHz); automatic gain control (40-ns window); prestack $f-k$ filtering to remove coherent noise; and PSDM with reflection tomography.

\section{Multi-offset results and interpretation}

Overall, the multi-offset data are good quality and adequate to meet the survey objectives. The primary source of coherent noise was air-wave scatter either from an overhead power line or from fences. Because the electromagnetic wave velocity in air is 2-4 times greater than that in the subsurface, this coherent noise is easily separated in the prestack CDP gathers and attenuated effectively using $f-k$ filtering (Figures 6 and 7).

The data show two apparent and different NAPL responses. The first response is a zone of decreased electric permittivity (increased velocity) just above the aquitard boundary (anomaly lines and Area 3, Figure 5), analogous to the results of the October 2000 survey (Figure 3). We refer to this response as a Type 1 anomaly. The second response is increased signal attenuation in areas thought to have significant NAPL accumulation (Areas 1 and 4), consistent with areas of increased electric conductivity as observed at other aged LNAPL sites (Atekwana et al., 2004a; Atekwana et al., 2002; Atekwana et al., 2004b). We refer to this response as a Type 2 anomaly. Here we focus on the Type 1 anomalies.

A deep paleo-channel mapped in Area 3 demonstrates the Type 1 anomaly (Figure 5). This channel is the deepest portion of the aquitard surface in the vicinity west of the CDPs. It is a likely contaminant transport route, particularly during

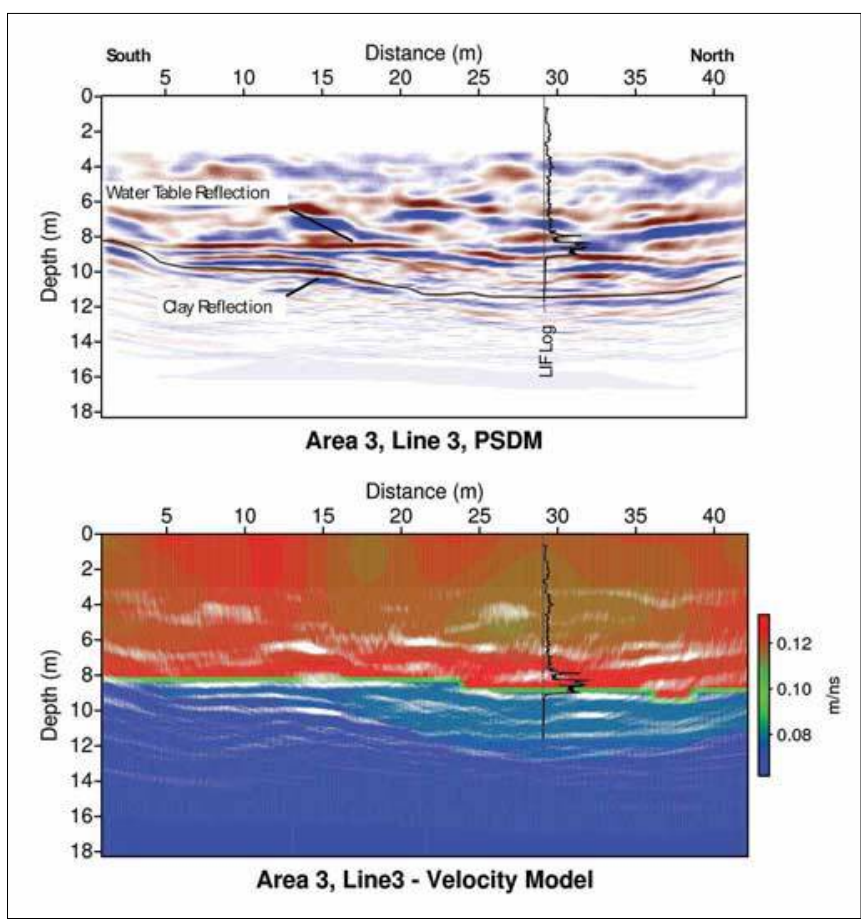

Figure 8. The upper image shows the PSDM result along Line A3L3 (Figure 5). The deep channel in the clay surface is partially filled with water. The zone of anomalous reflectivity 1-2 $m$ above the water table is associated with a high-velocity zone shown in the lower image. This zone was later found to have a substantial LIF anomaly and up to 5\% volumetric LNAPL contamination. 
low water-table conditions. Given the high probability of locating NAPL along this transport route, we targeted a 30-m section of the channel for multi-offset investigation. Multioffset analysis and PSDM imaging provided an excellent image of the channel (Figures 7 and 8), and the interpreted depth-to-clay at the base of the channel (12.6 $\mathrm{m}$ below datum (b.d.)) is within $0.6 \mathrm{~m}$ of the depth found during the subsequent CPT and borehole investigation (12 m b.d.).

Just above the water table is a zone, with thickness of $1-2$ $\mathrm{m}$, of anomalous reflectivity and this zone is associated with an elevated propagation velocity (Figure 8 ). A subsequent LIF probe $\log$ indicated the presence of a significant LNAPL accumulation just above the water table (Figure 8). Subsequent analysis of core samples verified the presence of LNAPL and found LNAPL saturations of up to 5\% (Sverdrup Technology Inc. and Intera Inc., 2003).

Of the anomaly lines, we identified high-velocity anomalies along anomaly lines 1, 2, and 4 (Figure 5). Along lines 2 and 4, a high-velocity anomaly was present within a topographic low analogous to that found in the 2000 survey. Along line 4, a LIF anomaly was found and was consistent with the location of the velocity anomaly (Figure 9). However, the LIF anomaly is very small and suggests a maximum LNAPL concentration of only around $1 \%$. The LIF location appears to have intersected the edge of the high-velocity anomaly and possibly missed the highest LNAPL concentration.

LNAPL-induced velocity anomalies observed in both Zone 3 and anomaly line 4 are substantially higher than would be predicted based on simple volumetric weighting of the constituent properties (e.g., the CRIM equation). As in the October 2000 investigation, this leaves the problem of explaining a large velocity anomaly with a relatively small LNAPL saturation. Our favored interpretation is that a small amount of weathered, highly viscous LNAPL is clogging the pore throats and limiting water entry into the anomalous zone. The low water saturation leads to high GPR velocity. This explanation is speculative, but could be tested by measuring water content in samples taken from within and around the anomalous zone.

\section{Summary of results}

Hill AFB, OU-1 presented three primary challenges:

- Significant heterogeneity in the surface material related to variations in fill material associated with capping, landfill, and remediation activities.

- Significant heterogeneity at the target depth. NAPL is present near the sand/clay boundary. Variable topography along this surface had a significant impact on contaminant migration. This was further complicated by seasonal water-table fluctuations about the sand/clay interface.

- Highly heterogeneous NAPL resulting in variable electric properties and heterogeneous contaminant migration and distribution.

In spite of these difficulties, GPR data quality was generally good and study objectives were met. The clay topography was

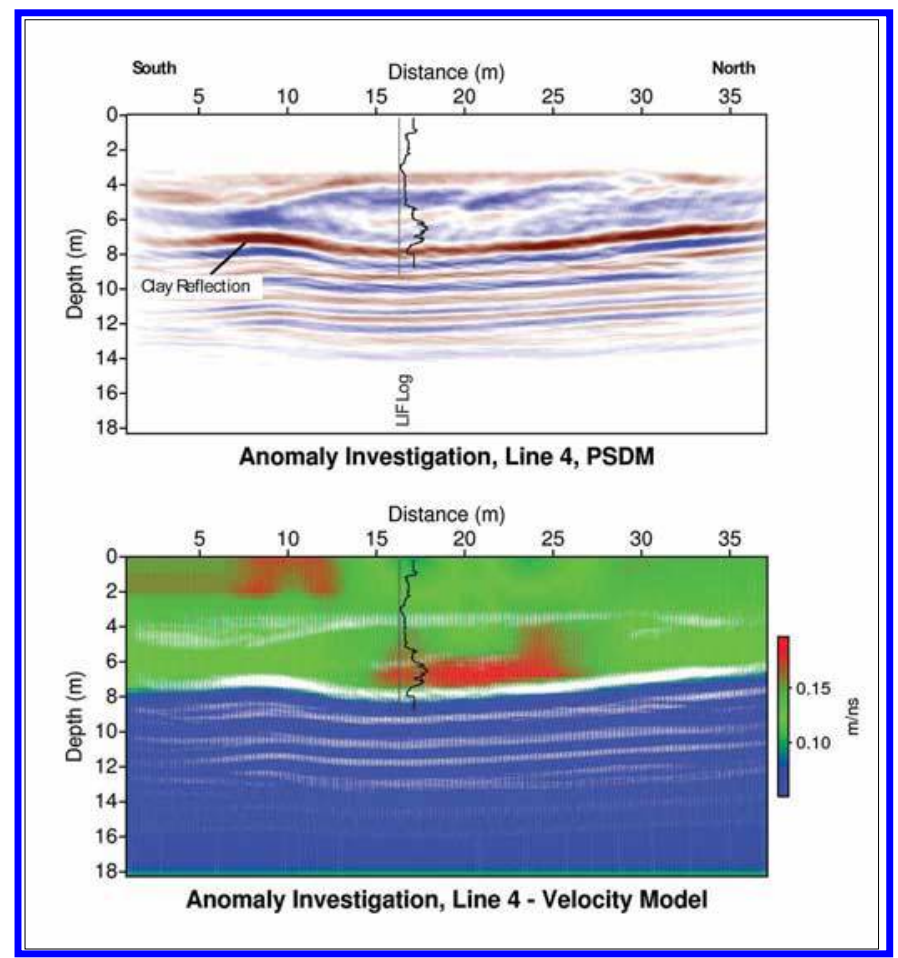

Figure 9. The upper image shows the prestack depth-migrated section along line ANL4 (Figure 5). The clay depression with low-amplitude overlying reflectivity was targeted for further investingation. The lower image show the results of reflection tomograpy. A high-velocity zone lying within the clay depression correlated with a LIF anomaly and indicates possible NAPL contamination.

imaged to less than $1 / 4$ of the dominant GPR wavelength over most of the site except in the southeast portion of the site in the vicinity of CDP 2. Here poor data quality caused by increased electric conductivity made it impossible to interpret the clay surface with confidence. The source of the increased conductivity is unknown but may be related to LNAPL biodegradation.

Through multi-offset profiling, we overcame some of these difficulties and improved imaging of the clay surface in high noise areas. Several locations had reflectivity and velocity anomalies analogous to the LNAPL contaminated zone investigated in our earlier 2000 pilot study. PSDM and reflection tomography were key to identifying these velocity anomalies. Of the four locations recommended as likely to contain LNAPL, two were sampled in the subsequent CPT effort. LIF probing and/or core sample analysis indicated that both sites had LNAPL accumulations.

The results of this study are encouraging and clearly show that GPR velocity analysis is useful in the field to locate and characterize LNAPL contaminant anomalies. The results are not unique, as distribution of different materials may produce identical geophysical responses. However, through careful, quantitative analysis and an understanding of site conditions we may identify zones that have a high probability of being contaminated.

Implications for best practices in contaminated site characterization

Prior to 2002, heterogeneity at the sand/clay boundary was not adequately characterized even through extensive coring. 
Maps based on direct sampling data alone were misleading and led to failure or inhibited performance of the designed remediation and containment systems. In contrast, the relatively low-cost GPR survey led to a substantial improvement in characterization of the site. Indirect improvement came via use of the geophysical results to guide the subsequent intensive coring and CPT campaign. Unfortunately, the extensive geophysical survey was not conducted until too late to have input to remediation planning, which leads one to wonder how much money would have been saved had the geophysics been conducted at the front end of site investigation. The new data showed why previous remediation efforts failed. While this case study makes a nice success story for geophysics, it also highlights the need to educate the contaminated site characterization and remediation community. THE

\section{References}

Atekwana, E. A., E. A. Atekwana, D. D. Werkema Jr., J. P. Allen, L. A. Smart, J. W. Duris, D. P. Cassidy, W. A. Sauck, and S. Rossbach, 2004a, Evidence for microbial enhanced electrical conductivity in hydrcarbon-contaminated sediments: Geophysical Research Letters, 31, no. 23, L23501, http://dx.doi.org/10.1029/2004GL021359.

Atekwana, E. A., W. A. Sauck, Z. G. Abdel Aal, and D. D. Werkema Jr., 2002, Geophysical investigation of vadose zone conductivity anomalies at a hydrocarbon contaminated site: Implications for the assessment of intrinsic bioremediation: Iournal of Environmental \& Engineering Geophysics, 7, no. 3, 103-110, http://dx.doi. org/10.4133/JEEG7.3.103.

Atekwana, E. A., D. D. Werkema Jr., J. W. Duris, S. Rossbach, E. A. Atekwana, W. A. Sauck, D. P. Cassidy, J. Means, and F. D. Legall, 2004b, In-situ apparent conductivity measurements and microbial population distribution at a hydrocarbon contaminated site: Geophysics, 69, no. 1, 56-63, http://dx.doi.org/10.1190/1.1649375.
Bradford, J. H., 2006, Applying reflection tomography in the postmigration domain to multi-fold GPR data: Geophysics, 71, no. 1, K1-K8. http://dx.doi.org/10.1190/1.2159051.

Bradford, J. H., 2008, Measuring lateral and vertical heterogeneity in vadose zone water content using multi-fold GPR with reflection tomography: Vadose Zone Iournal, 7, 184-193. http://dx.doi. org/10.2136/vzj2006.0160.

Bradford, J. H. and J. C. Deeds, 2006, Ground-penetrating radar theory and application of thinbed offset dependent reflectivity: Geophysics, 71, no. 3, K47-K57, http://dx.doi.org/10.1190/1.2194524.

Bradford, J. H. and Y. Wu, 2007, Instantaneous spectral analysis: Time-frequency mapping via wavelet matching with application to 3D GPR contaminated site characterization: The Leading Edge, 26, no. 8, 1018-1023, http://dx.doi.org/10.1190/1.2769559.

CH2MHILL, 2008, Five-Year Review for Hill Air Force Base.

Leparoux, D., D. Gibert, and P. Cote, 2001, Adaptation of prestack migration to multi-offset ground-penetrating radar (GPR) data: Geophysical Prospecting, 49, no. 3, 374-386, http://dx.doi. org/10.1046/j.1365-2478.2001.00258.x.

Lien, B. K. and C. G. Enfield, 1998, Delineation of subsurface hydrocarbon contaminant distribution using a direct push resistivity method: Journal of Environmental \& Engineering Geophysics, 2, no. 3, 173-179.

Pipan, M., E. Forte, M. Dal Moro, M. Sugan, and I. Finetti, 2003, Multifold ground-penetrating radar and resistivity to study the stratigraphy of shallow unconsolidated sediments: The Leading Edge, 22, no. 9, 876-881, http://dx.doi.org/10.1190/1.1614161.

Sverdrup Technology Inc. and Intera Inc., 2003, Operable Unit 1 Final Report: Source Zone Delineation Project.

Young, R. A. and J. Sun, 1996, 3D ground penetrating radar imaging of a shallow aquifer at Hill Air Force Base, Utah: Journal of Environmental and Engineering Geophysics, 1, no. 2, 97-108, http:// dx.doi.org/10.4133/JEEG1.2.97.

Corresponding author: jbradfor@boisestate.edu 